\title{
PATENT DUCTUS ARTERIOSUS IN INFANCY
}

\author{
BY \\ OLIVE SCOTT and G. F. GEARTY \\ From the Heart Clinic, Royal Liverpool Children's Hospital
}

(RECEIVED FOR PUBLICATION JANUARY 14, 1960)

In a report on 1,000 autopsies performed on patients dying of congenital heart disease, Abbott (1937) found that the principal lesion was a patent ductus arteriosus in 282 patients; $20 \%$ of these were infant deaths.

Subsequently numerous reports have stressed that while this abnormality can prove fatal during the first year of life, surgery in skilled hands offers an effective remedy at this age with negligible risk (Ziegler, 1952; Rudolph, Mayer, Nadas and Gross, 1958; Bauersfeld, Adkins and Kent, 1957).

Accurate diagnosis, however, may be difficult in infants. The classical continuous murmur so frequent in the older child (Hay and Ward, 1956) may not be heard, and interpretation of the signs which do present is not easy. In addition, the many complex cardiac abnormalities which are seen in infants give rise to special problems in differential diagnosis.

In this paper the clinical findings and results of ancillary investigations are analysed in 28 infants in whom patent ductus arteriosus was the sole cardiac lesion.

\section{Clinical Findings}

Symptoms and Physical Signs. The principal features of each case are set out in Table 1. Twentythree babies presented with dyspnoea and 21 had had bronchitis. Recurrent respiratory infections often severe and accompanied by marked breathlessness caused concern in 13 babies (46\%); dyspnoea, accentuated by feeding or crying, was common in this group and all 13 were under weight when first seen.

Heart failure as evidenced by peripheral oedema, hepatomegaly and lung crepitations occurred in four cases (Cases 1, 2, 11 and 14); in three it was precipitated by bronchopneumonia.

The 'waterhammer' character of the pulse was noted in all cases and often provided the first clue to the diagnosis. It was not always easily detected at the wrist, particularly in the restless infant, but was always readily felt in the tibial vessels at the ankle. In 17 infants $(60 \%)$ the waterhammer quality was very impressive.

A systolic thrill was noted in 12 cases ( $43 \%)$ and this was usually localized to the pulmonary area. A murmur which began after the first sound and which extended through the second sound into diastole was audible in 22 babies $(78 \%)$. The classical 'machinery' quality was rare, though a low-pitched systolic rattle was often heard. The murmur extended into diastole for a variable period but was seldom as long as the typical murmur in older children. We have, nevertheless, defined this murmur as being continuous because it continues through the second sound from systole into diastole as Gibson (1900) originally defined it. The continuous murmur was confined to the second left intercostal space, but the systolic element was widely conducted and sometimes even louder in the third or fourth left intercostal spaces close to the sternal edge. In the remaining six cases a continuous murmur was not present and the point of maximal intensity of the systolic murmur was difficult to determine. An independent apical mid-diastolic murmur was recorded in 18 infants $(64 \%)$. Four of these had no continuous murmur and the diastolic murmur was the most striking one; catheterization was done in three of these four cases and all three had marked pulmonary hypertension.

Radiography. Standard antero-posterior and oblique films were taken in all cases. Pulmonary plethora associated with some degree of cardiac enlargement was present in all. The cardiac contour was not in any way characteristic, though 14 infants $(50 \%)$ showed a well-defined pulmonary arc. Selective enlargement of the left ventricle was suggested in $18(64 \%)$, and of the left atrium in seven $(25 \%)$.

Electrocardiography. Standard and unipolar limb leads as well as four praecordial leads (V3R, V1, $\mathrm{V} 3$ and V6) were recorded in all cases. Interpretation was based on Ziegler's (1951) criteria. 


\begin{tabular}{|c|c|c|c|c|c|c|c|c|c|c|c|}
\hline \multirow{2}{*}{$\begin{array}{l}\text { Case } \\
\text { No. }\end{array}$} & \multirow{2}{*}{ Age } & \multicolumn{3}{|c|}{ Symptoms } & \multicolumn{4}{|c|}{ Signs } & \multicolumn{3}{|c|}{ Radiograph } \\
\hline & & Dyspnoea & Bronchitis & $\begin{array}{c}\text { Heart } \\
\text { Failure }\end{array}$ & Thrill & C.M. & M.D.M. & B.P. & C.T. ratio & L.A. & L.V \\
\hline 1 & 12 & ++ & ++ & + & + & 0 & + & 95 syst. & 0.7 & $\mathbf{N}$ & $\mathbf{N}$ \\
\hline 2 & $\begin{array}{c}24 \\
\text { days }\end{array}$ & + & + & + & 0 & + & + & $100 / 0$ & 0.68 & + & $\mathbf{N}$ \\
\hline 3 & $\begin{array}{c}\text { oays } \\
7 \\
\text { weeks }\end{array}$ & ++ & ++ & 0 & + & + & + & $100 / 0$ & 0.66 & $\mathbf{N}$ & + \\
\hline 4 & $\begin{array}{c}8 \\
8\end{array}$ & ++ & + & 0 & 0 & + & + & $110 / 40$ & $0 \cdot 6$ & $\mathbf{N}$ & + \\
\hline 5 & $\begin{array}{l}3 \\
3 \\
m \text { nths }\end{array}$ & ++ & + & 0 & 0 & + & 0 & 85 syst. & 0.67 & + & + \\
\hline 6 & $\begin{array}{l}4 \\
4 \\
\text { mths }\end{array}$ & $+t$ & ++ & 0 & 0 & 0 & + & 75 syst. & 0.63 & $\mathbf{N}$ & $\mathrm{N}$ \\
\hline 7 & 4 & + & + & 0 & 0 & + & + & $120 / 55$ & 0.65 & + & + \\
\hline 8 & 5 & ++ & 0 & 0 & + & + & + & $105 / 0$ & 0.67 & + & + \\
\hline 9 & 5 & $+t$ & + & 0 & 0 & + & 0 & not & $0 \cdot 6$ & $\mathbf{N}$ & + \\
\hline 10 & 5 & $+t$ & + & 0 & 0 & + & 0 & $\begin{array}{l}80 / 0 \\
80\end{array}$ & 0.56 & $\mathbf{N}$ & $\mathbf{N}$ \\
\hline 11 & $\begin{array}{c}\text { mths } \\
5\end{array}$ & ++ & 0 & + & 0 & + & + & $120 / 70$ & 0.67 & $\mathbf{N}$ & + \\
\hline 12 & $\begin{array}{c}\text { miths } \\
5 \\
\text { mths }\end{array}$ & + & + & 0 & + & 0 & 0 & not & 0.6 & $\mathbf{N}$ & $\mathrm{N}$ \\
\hline 13 & 5 & + & 0 & 0 & 0 & + & 0 & $115 / 75$ & 0.62 & $\mathbf{N}$ & $\mathrm{N}$ \\
\hline 14 & $\underset{5}{\mathrm{mths}}$ & ++ & ++ & + & 0 & 0 & + & not & 0.63 & $\mathbf{N}$ & + \\
\hline 15 & 6 & ++ & $+t$ & 0 & 0 & 0 & 0 & $\begin{array}{c}\text { recorded } \\
110 / 70\end{array}$ & 0.58 & $\mathbf{N}$ & + \\
\hline 16 & 6 & 0 & + & 0 & + & + & + & 95 syst. & 0.59 & + & + \\
\hline 17 & 6 & ++ & ++ & 0 & + & 0 & + & $95 / 10$ & $0 \cdot 61$ & $\mathbf{N}$ & $+t$ \\
\hline 18 & 6 & 0 & + & 0 & + & + & + & $120 / 60$ & 0.62 & $\mathbf{N}$ & ब্्र \\
\hline 19 & 7 & $t+$ & 0 & 0 & + & + & + & $110 / 60$ & $0 \cdot 7$ & $\mathbf{N}$ & \$ \\
\hline 20 & $\underset{8}{\mathrm{mins}}$ & + & ++ & 0 & 0 & + & 0 & not & 0.6 & $\mathbf{N}$ & $\underline{\bar{\theta}}$ \\
\hline 21 & 9 & 0 & ++ & 0 & 0 & + & 0 & $100 / 0$ & 0.6 & $N$ & $\bar{N}$ \\
\hline 22 & 9 & + & 0 & 0 & 0 & + & + & $120 / 70$ & $0 \cdot 8$ & + & $\div$ \\
\hline 23 & $\underset{9}{\text { mins }}$ & + & + & 0 & 0 & + & + & $100 / 0$ & 0.64 & + & $\mathbf{N}$ \\
\hline 24 & 10 & + & 0 & 0 & 0 & + & 0 & $100 / 0$ & 0.6 & $\mathbf{N}$ & + \\
\hline 25 & $\begin{array}{c}\text { miths } \\
10\end{array}$ & ++ & ++ & 0 & + & + & + & $115 / 55$ & 0.64 & $\mathbf{N}$ & +4 \\
\hline 26 & ${ }_{11}^{\mathrm{mins}}$ & + & + & 0 & t & + & 0 & $120 / 70$ & 0.59 & $\mathbf{N}$ & + \\
\hline 27 & $\begin{array}{c}\text { mens } \\
11\end{array}$ & 0 & ++ & 0 & + & + & + & $95 / 45$ & $0 \cdot 58$ & $\mathbf{N}$ & + \\
\hline 28 & $\begin{array}{c}\text { mits } \\
12 \\
\text { mths }\end{array}$ & 0 & 0 & 0 & + & + & + & $\begin{array}{c}\text { not } \\
\text { recorded }\end{array}$ & 0.57 & $\mathbf{N}$ & + \\
\hline
\end{tabular}

Vertical or semi-vertical electrical position was usual: only one horizontal heart was found. The electrical axis was normal in $23(82 \%)$, four showed right axis deviation and one left axis deviation. There was evidence of left atrial enlargement in four patients. In $13(46 \%)$ ventricular activity was normal. Left ventricular hypertrophy was evident in 11 records $(40 \%)$, always with an isoelectric S.T. segment and a normal upright $\mathrm{T}$ wave in the left ventricular leads. Combined right and left ventricular hypertrophy was recorded in four cases $(14 \%)$ while isolated right ventricular hypertrophy was present in only one (Case 19).
A pattern consisting of large RS deflections over the right ventricle with normal activity in left ventricular leads and deep $Q$ waves in leads 111 and aVF was recorded in eight cases $(28 \%)$. In all of these the duct measured $7 \mathrm{~mm}$. or more (Cases $1,6,8,11,12,15,22$ and 28) and in three there was marked pulmonary hypertension (Cases 1, 6 and 15 ).

The prevalence of deep $Q$ waves in this series was an interesting feature. They were invariably present in lead V6, measuring $3 \mathrm{~mm}$. or more in 12 instances $(43 \%)$. Twenty-three infants $(80 \%)$ showed a deflection of $3 \mathrm{~mm}$. or more in either lead 


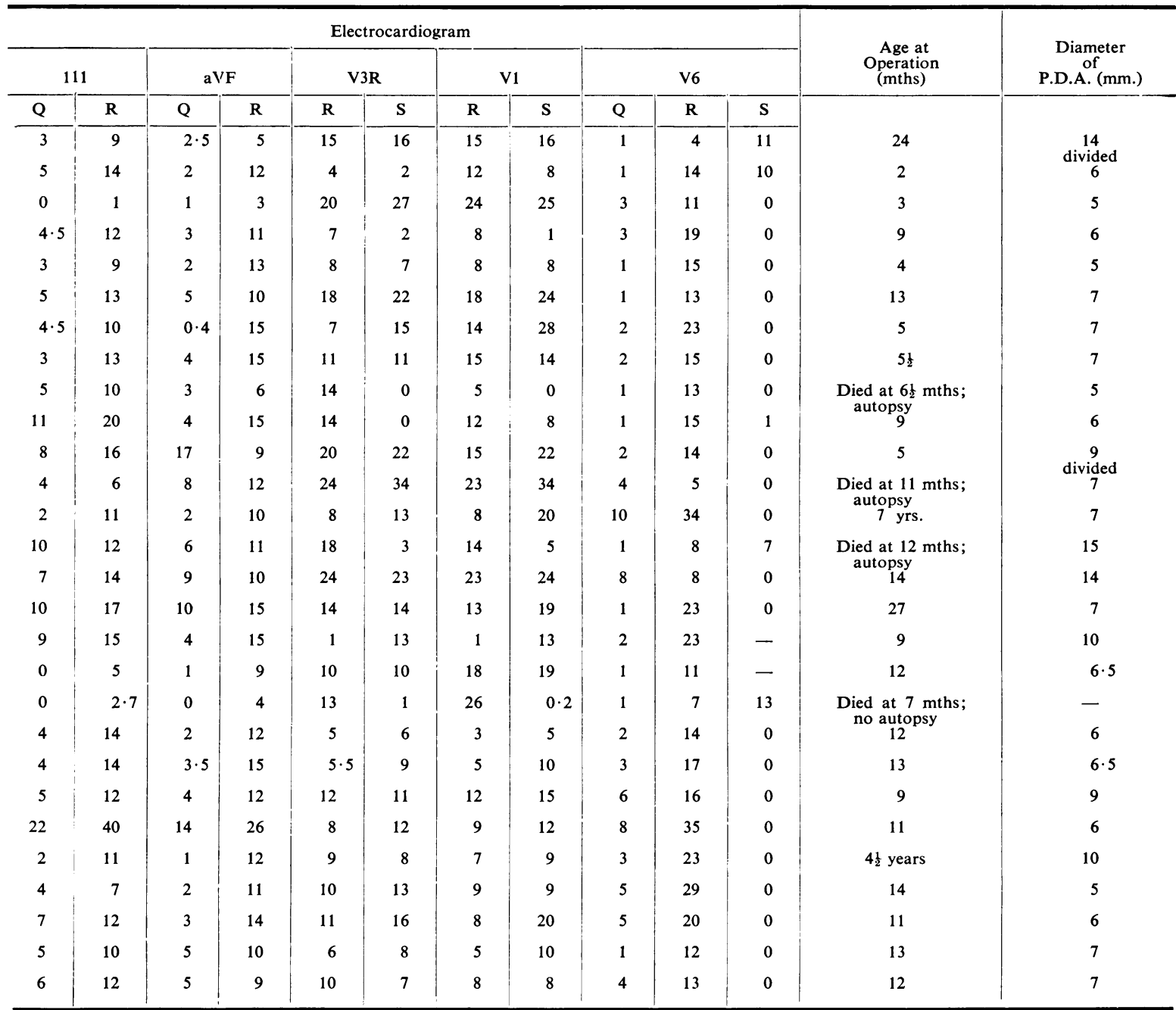

111 or aVF. The amplitude of the QRS complexes in leads 111, aVF, V3R, V1 and V6 are tabulated (Table 1).

Special Investigations. Cardiac catheterization was performed in four of the 28 infants (Cases 1, 6, 15 and 17) in whom the diagnosis remained uncertain after clinical, electrocardiographic and radiographic examination (Table 2). All had marked pulmonary hypertension and in three (Cases 1,6 and 15) the greatest difference between the pulmonary artery and aortic pressures during sedation was $4 \mathrm{~mm}$. $\mathrm{Hg}$. In one of these there was evidence of a left to right shunt through the ductus but in the other two the diagnosis was confirmed by passing the catheter into the descending aorta.

Venous angiocardiography was carried out in one (Case 3) when the catheter could not be advanced into the pulmonary artery. This showed dilatation of the left pulmonary artery with dilution of the contrast medium in the artery at the site of entry of the patent ductus.

\section{Treatment}

When heart failure was present it was treated with digoxin and diuretics. Pulmonary infections 
TABLE 2

CARDIAC CATHETERIZATION

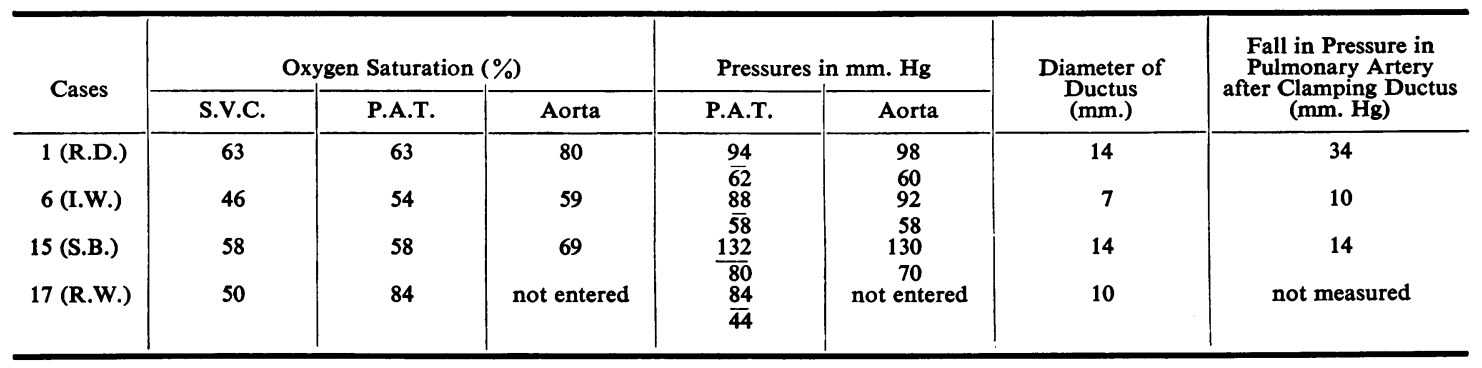

were treated with antibiotics. All the patients responded satisfactorily to treatment and operation was never performed in the presence of heart failure or infection.

The ductus was either ligated or divided, depending on its size, in 24 of the 28 infants. There were no deaths and closure was incomplete in only one infant in whom the duct was found to be broad and frail. The age at operation and minimum external diameter of the ductus is tabulated (Table 1).

The remaining four infants (Cases 9, 12, 14 and 19) died while awaiting admission for further assessment and operation. Two of these had other serious abnormalities (one, Case 14, had Albers-Schönberg's disease, and the other, Case 9, had Möbius' syndrome); one, Case 19, developed fulminating gastroenteritis, and the fourth baby, Case 12, developed bronchopneumonia at home and died.

\section{Differential Diagnosis}

In the majority of infants patency of the ductus may be differentiated from other lesions with confidence after clinical examination, radiography, electrocardiography and phonocardiography. In some babies, on the other hand, a large patent ductus may present without any of the typical signs and differential diagnosis is difficult. The lesions with which patent ductus arteriosus is most commonly confused in the early months of life are persistent truncus arteriosus and ventricular septal defect. Another important consideration is that a patent ductus may be compensating for a more serious underlying lesion and this possibility must always be borne in mind.

The following case summaries are detailed to illustrate the problems involved in the diagnosis of patent ductus arteriosus. The first two cases (Case 2 and Case 1) show that the clinical picture of a small ductus without pulmonary hypertension differs widely from that of a large ductus with pulmonary hypertension at systemic level. The third case shows how even when the ductus is compensatory it may dominate the clinical picture.

The fourth case shows how closely persistent truncus arteriosus may resemble patent ductus arteriosus in the first few months of life.

B.L. Case 2. Small patent ductus. Normal delivery followed an uncomplicated pregnancy. The birth weight was $7 \mathrm{lb} .4 \mathrm{oz}$. Bronchopneumonia at 2 weeks of age led to admission to hospital, where heart failure was diagnosed in addition to pneumonia. Improvement followed therapy with penicillin and digoxin. He was transferred to this clinic when $3 \frac{1}{2}$ weeks old. At that time he weighed $5 \mathrm{lb}$., was poorly nourished and had slight dyspnoea at rest. There was a waterhammer arterial pulse and a continuous murmur in the pulmonary area with an independent apical mid-diastolic murmur. Phonocardiography showed that the murmur began after the first sound, reached a late systolic crescendo and extended without interruption into early diastole (Fig. 1). Both aortic and pulmonary valve closure were clearly recorded in the second left intercostal space. The heart was enlarged radiologically (C.T. ratio 0.68 ) with selective enlargement of the left atrium and there was pulmonary hyperaemia. The electrocardiogram was normal.

At thoracotomy a patent ductus arteriosus of minimal external diameter $6 \mathrm{~mm}$. was transfixed and ligated. Progress since then has been entirely satisfactory. The child is gaining weight well and has no dyspnoea. His heart sounds are normal and there are no murmurs.

CoMment. In this case the clinical, radiographic, electrocardiographic and phonocardiographic appearances were typical of a patent ductus which was confirmed at thoracotomy.

R.D. Case 1. Large patent ductus arteriosus with marked pulmonary hypertension. This male infant was born by normal delivery after eight months of uncomplicated pregnancy and weighed $5 \mathrm{lb}$. $13 \mathrm{oz}$. at birth. Normal respirations developed spontaneously and his general condition seemed satisfactory. Heart failure developed on the third day of life and a loud systolic murmur was noted. 

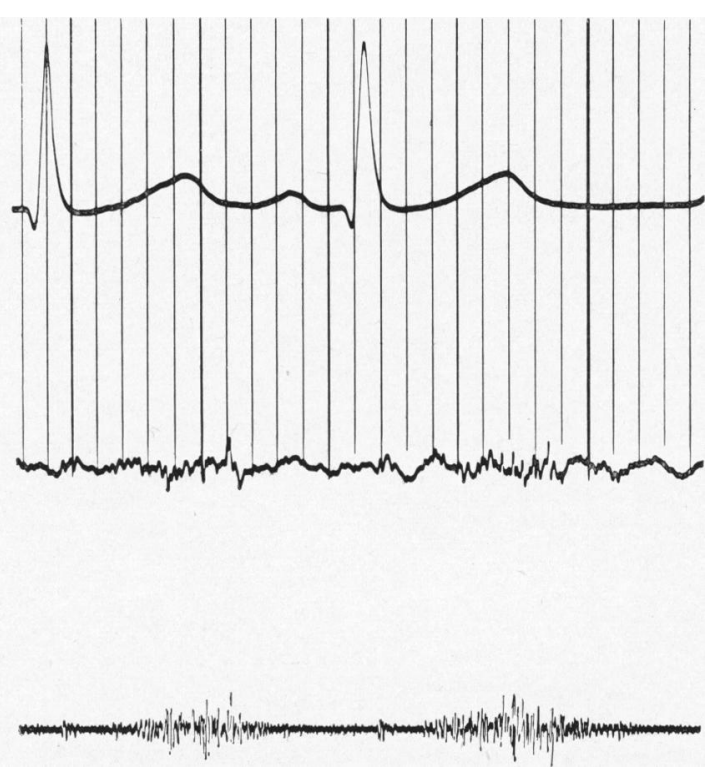

Fig. 1.-Phonocardiogram recorded from second left interspace showing continuous murmur with late systolic accentuation.

When first seen at this clinic on the 12th day of life, his condition had improved following digoxin therapy though dyspnoea and moderate oedema of the extremities persisted, and some fine crepitations were noted at the base of the right lung. The arterial pulses were regular and of 'full' volume. A long systolic murmur of lowpitched blowing quality was heard in the pulmonary area and down the left sternal edge, the point of maximum intensity being uncertain. No diastolic murmur was, heard. is

Radiography showed marked generalized cardiac enlargement and increased pulmonary vascularity.

Electrocardiography showed right axis deviation, a vertical heart and large $R / S$ deflections over the right ventricle (R V3R $15 \mathrm{~mm}$., S V3R $16 \mathrm{~mm}$.). In the left ventricular leads tall $T$ waves suggested left ventricular diastolic overload, though the height of the $R$ waves were within normal limits (R V6 $4 \mathrm{~mm}$.). A provisional diagnosis of ventricular septal defect was made.

Progress. The signs of congestive failure gradually disappeared with continued digoxin therapy. Dyspnoea persisted and at 6 weeks the infant weighed only $5 \mathrm{lb} .10 \mathrm{oz}$. He was seen regularly in the clinic and his progress over the next two years was punctuated by monthly attacks of bronchitis, occasional cyanotic episodes, usually associated with feeding difficulties, and persistent moderate dyspnoea at rest. He gained weight slowly and was only $23 \mathrm{lb}$. at 2 years. He did not stand with support until he was 2 years old and had not begun to walk at that age. The clinical signs in the cardiovascular system varied little throughout this period. The arterial pulses were always of full volume and a waterhammer quality was occasionally recorded. The systolic murmur persisted and latterly was accompanied by a faint systolic thrill in the second and third left intercostal spaces. The second sound in the pulmonary area was accentuated and finely split.

Cardiac enlargement was a constant radiological finding but became relatively less marked with age. The pulmonary arc became more clearly defined after the second month. A moderate degree of pulmonary plethora persisted.

In the electrocardiogram the pattern of the precordial leads varied little; the amplitude of the individual deflections showed occasional fluctuations, but these were never constant in any one direction. At the age of 2 years left ventricular overactivity was still indicated by large $S$ waves in the right ventricular leads (S V1 $25 \mathrm{~mm}$.). By this time right ventricular hypertrophy was also suggested (R V1 $20 \mathrm{~mm}$.), and impressive Q waves had developed in standard lead 111 and unipolar limb lead aVF. These $Q$ waves first appeared when the child was 3 months old and gradually became deeper.

The diagnosis was established when the child was 2 years old by cardiac catheterization, the descending aorta being easily entered through a large patent ductus. There was little change in pressure when the catheter was withdrawn from the aorta to the pulmonary artery and oxygen saturation figures failed to show a left to right shunt at pulmonary artery level when the child

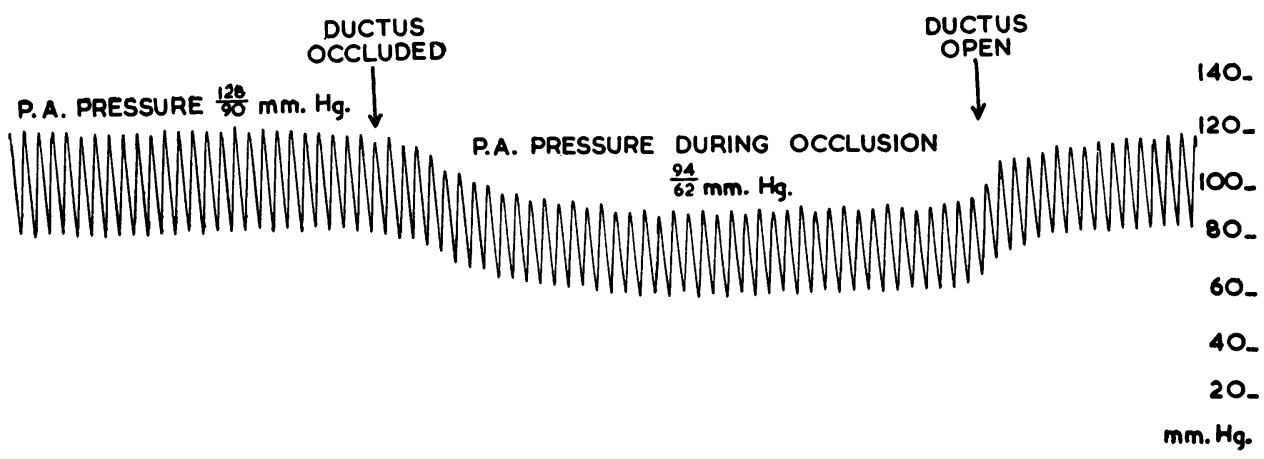

FIG. 2.-Pressure tracing from pulmonary artery at thoracotomy in Case 1, showing fall in pulmonary artery pressure after occlusion of the ductus. 

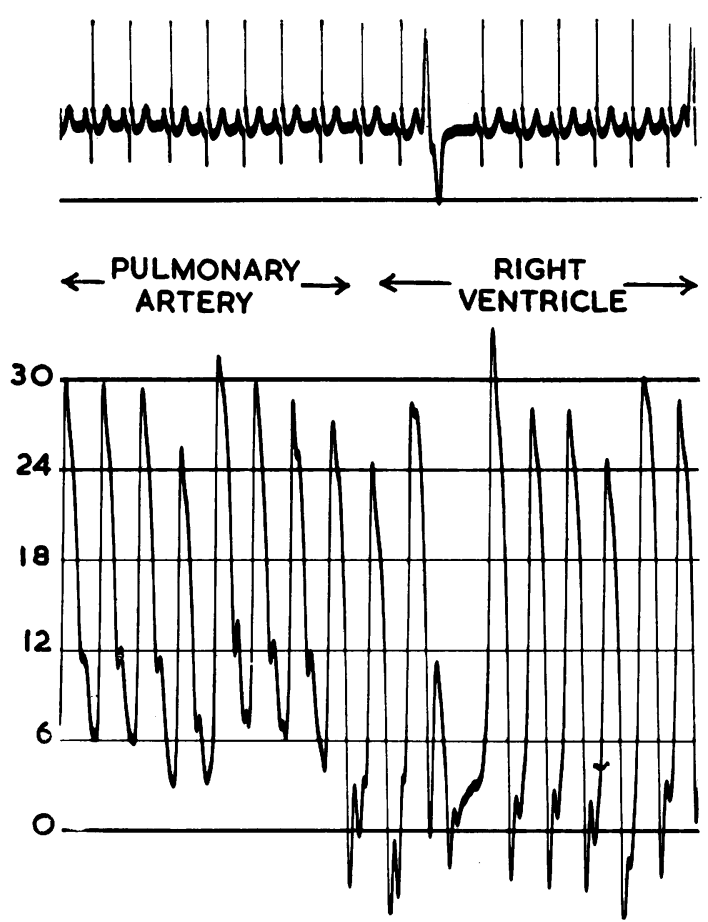

Fig. 3.-Pressure tracing showing normal pressures in pulmonary artery and right ventricle in Case 1, 13 months after operation.

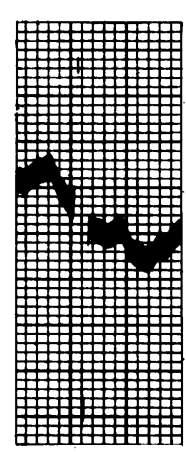

$V_{3 R}$

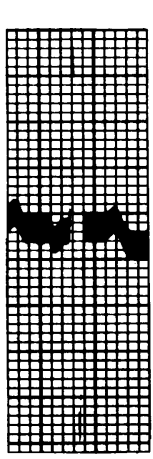

$v_{1}$

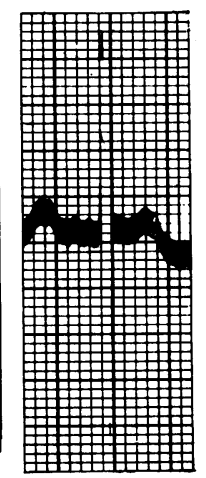

$v_{3}$

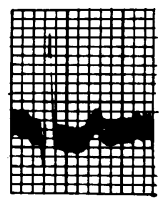

FIG. 4.-Electrocardiogram showing increased $\mathbf{R}$ and $\mathbf{S}$ waves in $V 3 R$ and $V 1$ with a normal $R$ wave in V6, a pattern commonly seen in large patent ducts with marked pulmonary hypertension.

was sedated at catheterization (Table 2). Thoracotomy was recommended and a. 14-mm. ductus was found. The pressure in the pulmonary artery fell markedly after clamping of the duct (Fig. 2) which was then divided.

The child's general condition rapidly improved following operation and breathlessness became less marked. His subsequent progress has been excellent with marked increase in activity; he has gained weight more quickly and has been completely free from attacks of bronchitis.

Recatheterization performed 13 months after operation showed a normal right ventricular and pulmonary artery pressure (Fig. 3). Chest radiographs show some pulmonary hyperaemia but the heart size is now normal. The electrocardiogram has also reverted to normal though prominent $Q$ waves persist in leads 11,111 , and aVF.

COMmEnT. This case illustrates how a large patent ductus arteriosus with pulmonary hypertension at systemic level may be mistaken for a more serious lesion. This led to delay in carrying out special investigations which enabled the diagnosis to be made.

Three other infants in this series (Cases 6, 14 and 15) presented similar features and catheterization established the diagnosis in two (Cases 6 and 15, Table 2). All three were dyspnoeic, under weight and suffered from recurrent pulmonary infections. All had 'waterhammer' pulses of a variable degree and two had apical middiastolic murmurs. All showed similar electrocardiographic records (Fig. 4), and all had some cardiac enlargement and pulmonary plethora. In these three babies the clinical signs were inconclusive and the results of routine investigations equivocal. It seems that all such obscure cases should be catheterized at an early age if surgical treatment is to be performed while the pulmonary hypertension is still completely reversible.

D.G. Compensatory Patent Ductus Arteriosus. This infant was the first of binovular twins born by breech delivery at full term. She then weighed $4 \mathrm{lb} .12 \mathrm{oz}$. Late pregnancy had been complicated by moderate toxaemia. There was a history of breathlessness since birth, but cyanosis had not been noticed. Pulmonary infection occurred during the third week of life and cardiac failure developed.

On admission to this clinic at 3 weeks of age the infant was pink and breathless with oedema of feet, arms and eyelids. The arterial pulse was waterhammer in character and a long systolic thrill was present in the pulmonary area. There was a long rattling systolic murmur extending into early diastole in the pulmonary area and an independent mid-diastolic murmur at the apex.

Radiography showed marked cardiac enlargement (C.T. 0.72 ) and moderate pulmonary hyperaemia (Fig. 5).

Electrocardiography showed right atrial enlargement (P2 $=3 \mathrm{~mm}$. peaked) with low voltage complexes in V3R and V1 and left ventricular hypertrophy with depression of the S-T. segments and inverted $\mathrm{T}$ waves in V5 and V6.

Treatment with digoxin and diuretics was followed by some improvement, but feeding remained difficult and she did not gain weight. Heart failure persisted despite treatment. Thoracotomy was therefore recommended when she was 6 weeks of age and a $6 \mathrm{~mm}$. patent ductus was ligated. Following operation the infant's condition deteriorated still further and she died 12 hours later. Autopsy showed tricuspid atresia. 


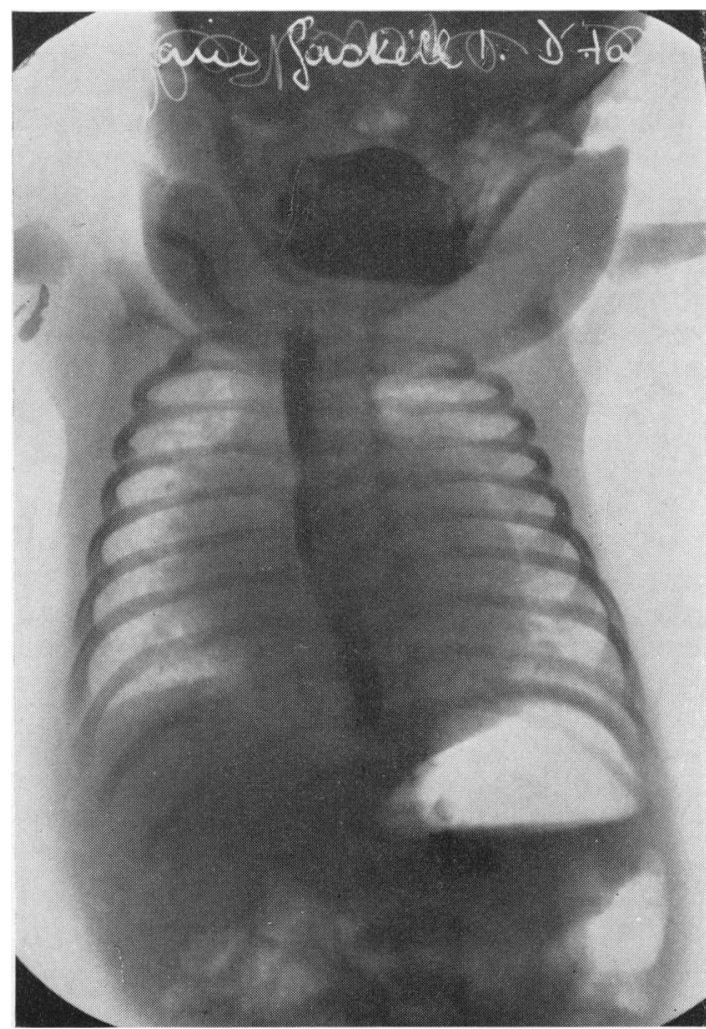

Fig. 5.-Radiograph showing plethoric lung fields in case of tricuspid atresia with overcompensating patent ductus arteriosus.

Comment. This case illustrates the extent to which a patent ductus arteriosus may completely dominate the clinical picture even though it is compensating for a lesion which causes pulmonary oligaemia.

Our experience of such dominance is, however, limited to tricuspid atresia, for all our babies with Fallot's tetralogy and pulmonary atresia with a patent ductus, have shown not only central cyanosis, but also normal or diminished pulmonary vascularity.

The fact that heart failure did not respond to medical treatment in this infant and the presence of left ventricular strain in the electrocardiogram should have made the diagnosis of a simple patent ductus arteriosus suspect. In a subsequent similar case attention to these findings enabled us to diagnose the same combination of defects, which were subsequently proved at autopsy.

D.E. Case of Persistent Truncus Arteriosus. This premature infant was born by normal delivery after eight months uncomplicated pregnancy. Initial progress was satisfactory, but increasing breathlessness was noted from the 5 th week. On admission to this clinic when 11 weeks old she was pink and moderately dyspnoeic at rest. The waterhammer quality of the arterial pulse was striking. Blood pressure was $120 / 0 \mathrm{~mm}$. $\mathrm{Hg}$.
A continuous murmur was heard in the pulmonary area and there was an apical mid-diastolic murmur. Phonocardiography confirmed these findings, but the second sound was not seen owing to the high amplitude of the murmur.

Radiologically the heart was enlarged (C.T. ratio $0 \cdot 75$ ) the oblique views showed selective left ventricular enlargement, and there was increase in the pulmonary vascularity.

The electrocardiogram showed left ventricular hypertrophy with $1 \mathrm{~mm}$. S-T depression and $\mathrm{T}$ wave inversion in leads V5 and V6. Right ventricular activity was within normal limits.

The diagnosis of patent ductus arteriosus was made and thoracotomy recommended. At operation, however, a persistent truncus arteriosus was found. The infant's condition deteriorated rapidly during exploration of the chest; ventricular fibrillation developed and she died.

Comment. In this case clinical examination suggested a patent ductus arteriosus. The picture was, however, incomplete because splitting of the second sound in the pulmonary area was neither audible nor clearly seen on the phonocardiogram and left ventricular systolic overload in the electrocardiogram was an unusual finding in patent ductus arteriosus in infancy.

This infant is one of a group of 10 cases of persistent truncus arteriosus seen at this clinic. Although cyanosis was prominent in half of these babies the other five were pink when first seen and presented many of the typical features of patent ductus arteriosus. The five acyanotic infants had markedly collapsing pulses and two of them had continuous basal murmurs with independent apical mid-diastolic murmurs. Radiographic and electrocardiographic appearances were similar to those seen in patent ductus arteriosus. These acyanotic infants had severe symptoms and after observation for a few weeks slight cyanosis with feeding became evident and led to further investigation in all except the case described. In two cases, cardiac catheterization demonstrated a left-to-right shunt at pulmonary artery level, but venous angiocardiography failed to reveal the common truncus and patent ductus arteriosus was wrongly diagnosed; both these patients died at thoracotomy. In the other two cases selective angiocardiography with injection of dye into the right ventricle outlined the common trunk and thoracotomy was avoided.

Slight cyanosis after crying or feeding is an extremely important feature in these cases. Angiocardiography is required to make the diagnosis, for cardiac catheterization alone may fail to indicate the ventricular septal defect which is always present with persistent truncus arteriosus, and the increased oxygen level in the blood in the common trunk suggests patent ductus arteriosus. If the right ventricular pressure is at systemic level and the catheter is not passed through a ductus into the descending aorta persistent truncus arteriosus should be suspected and selective angiocardiography should be performed.

Signs of left ventricular systolic overload in the electro- 
cardiogram occurred in three cases of truncus arteriosus, but none of the patent ducts, so this should always suggest the possibility of truncus arteriosus. If phonocardiography shows two sounds due to the independent closure of the aortic and pulmonary valves, persistent truncus arteriosus is eliminated.

\section{DISCUSSION}

\section{Diagnosis}

Clinical Signs. Most authors have emphasized the value of the bounding or brisk peripheral pulses and wide pulse pressure in the diagnosis of patent ductus arteriosus, though varying emphasis is based on their importance. This characteristic pulse persists even during tachycardia or heart failure, as long as the dominant shunt is from aorta to pulmonary artery (Ziegler, 1952). When, however, complete reversal of flow through the ductus occurs the pulses are of normal or small volume (Anderson, Adams and Varco, 1956). Complete reversal of flow is rare in infancy so the waterhammer pulse frequently provides an early clue to diagnosis. It was present in all our cases and we agree with Reinhold (1958) that it is the most important diagnostic sign. There is usually a wide pulse pressure, the aortic diastolic pressure being low; nevertheless, waterhammer pulses were also prominent in those infants with marked pulmonary hypertension; this is probably because the ductus in such cases is a large one and a significant left-to-right shunt still occurs even though the pulmonary artery pressure is very close to the systemic pressure. Indeed, in the presence of marked pulmonary hypertension a waterhammer pulse may be the only clinical sign which suggests a diagnosis of patent ductus arteriosus.

Waterhammer pulses may occur in conditions other than a patent ductus arteriosus, but the most marked examples of such pulsation were observed in acyanotic infants with persistent truncus arteriosus.

The proportion of cases with a continuous murmur varies considerably in published reports of series of patent ductus arteriosus. This may be due in part to the varying number of infants with marked pulmonary hypertension in each series. In addition, the interpretation of the term 'continuous murmur' varies; it is used in this clinic when the murmur continues through the second sound into diastole regardless of its duration in diastole. In our series all cases uncomplicated by marked pulmonary hypertension did have a continuous murmur when first seen, the youngest being 24 days old (Case 2). The typical machinery qualities of the murmur were uncommon, but a characteristic systolic rattle or crackle as described by Keith, Rowe and Vlad (1958) was often heard.

A mid-diastolic murmur, attributed to increased flow through the normal mitral valve, was a common finding and gave rise to triple rhythm at the apex. Since in some infants this may be the most striking praecordial murmur, even in the presence of marked pulmonary hypertension, its presence should always suggest the possibility of patent ductus arteriosus. An identical murmur, however, may occur in association with ventricular septal defect, persistent truncus arteriosus, aorto-pulmonary window and congenital mitral stenosis.

Of particular interest are the three patients (Cases 1,6 and 15) in whom the pulmonary artery and aortic pressures were so close. All these patients showed a fall in pulmonary artery pressure when the ductus was clamped at operation and all have done extremely well since operation. In the one which has been recatheterized, the right ventricular and pulmonary artery pressures are normal and there is no evidence of a shunt. This illustrates that despite almost balanced pressures in the pulmonary artery and aorta, the pulmonary artery pressure could revert to normal after treatment and that the factors contributing to the marked hypertension were completely reversible. We do not know when irreversible changes may develop in such a case, but it seems that the earlier the diagnosis is established and treatment carried out the more likely is a complete cure. We stress then the importance of finding a collapsing pulse in an acyanotic patient who may or may not have an apical diastolic murmur, who has plethoric lung fields on the radiograph and electrocardiogram changes described in Case 1. Catheterization should be carried out in the hope of finding a patent ductus arteriosus.

Phonocardiography. Experience with recent cases in this clinic has confirmed the findings of Reinhold and Nadas (1954) in the older child and convinced us of the value of phonocardiography. The graphic record illustrates the onset of the murmur after the first sound and its late systolic accentuation, and confirms its uninterrupted extension into diastole (Fig. 6). Though the loud murmur may mask the second heart sound at the base of the heart, exploration of the whole precordium is worth while as the separate closure of the aortic and pulmonary valves can often be recorded from the lower sternal edge (Fig. 6). The demonstration of these two independent sounds is important in the exclusion of a persistent truncus arteriosus. 


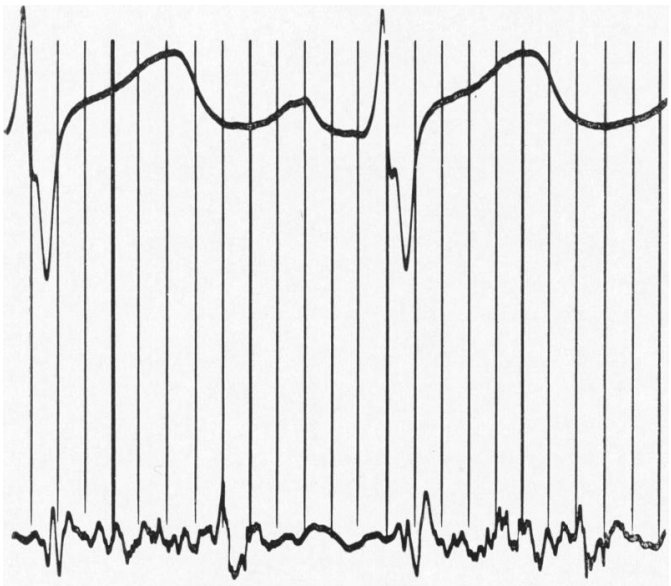

SPLITTING OF ' $P_{2}$ '

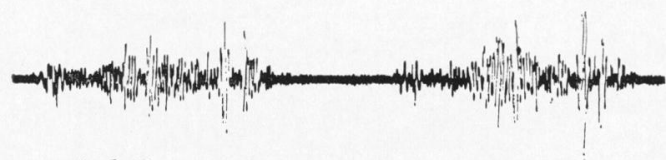

L.S.E.

Fig. 6.-Phonocardiogram showing continuous murmur. The two components of the second heart sound were best recorded at the left sternal edge.

Radiography. Some cardiac enlargement and pulmonary plethora is invariable and left ventricular or left atrial enlargement common. The pulmonary arc is often prominent after the early months of life and both this vessel and the aortic knuckle pulsate vigorously on screening. These appearances, though frequent in patent ductus arteriosus, are also found in other lesions, particularly ventricular septal defects.

Electrocardiography. The electrocardiogram may be within normal limits even though the child has symptoms and there is convincing clinical and radiological evidence of a left-to-right shunt (Cases 1,8 and 22) or marked pulmonary hypertension (Dammann and Sell, 1952). In most cases, however, the electrocardiogram is abnormal. In this series, evidence of isolated left ventricular hypertrophy was the commonest finding. Isoelectric S-T segment and upright $\mathrm{T}$ waves of normal or increased amplitude were always present in the left ventricular leads. In contrast, $\mathrm{T}$ wave inversion with or without S-T depression appeared in two cases of persistent truncus arteriosus and in both patients in whom tricuspid atresia accompanied patency of the ductus.
Though left ventricular strain may occur in older children with large uncomplicated patent ducts (Cosh, 1957; Hay and Ward, 1956), when it is thought to be due to coronary insufficiency, its presence in infancy makes us suspect some other lesion.

Isolated right ventricular hypertrophy was seen in only one case (Case 19). Clinical examination of this patient did not suggest either the presence of marked pulmonary hypertension or an associated pulmonary stenosis. Unfortunately the child died from fulminating gastroenteritis and autopsy was not allowed. Bauersfeld et al. (1957) have, however, reported the presence of isolated right ventricular hypertrophy in patent ductus arteriosus without pulmonary hypertension or pulmonary stenosis being present.

Rudolph et al. (1958) stated that combined ventricular hypertrophy frequently occurs in infants with patent ductus arteriosus and this was present in four of our cases (Cases 1, 3, 12 and 15). In these records, left ventricular hypertrophy was diagnosed because of the deep $S$ waves in V3R and $\mathrm{V} 1$; the $\mathrm{R}$ wave in $\mathrm{V} 6$ was not increased in amplitude. The three infants who were proved at cardiac catheterization to have marked pulmonary hypertension showed this pattern on the electrocardiogram and in all three the $Q$ waves were deep in leads 111 and aVF. Unfortunately, all the large ducts have not shown these features and identical records have been found in ventricular septal defects. Nevertheless, when these electrocardiographic changes occur in an infant the possibility of patent ductus arteriosus should be considered.

Deep $\mathbf{Q}$ waves are a common feature in infant records in leads 111 and aVF occurring in $40 \%$ of normal infants. Nevertheless, deep $\mathbf{Q}$ waves occurred in $80 \%$ of the infants who had patent ductus arteriosus and their presence may be of help in differential diagnosis as they are in the adult patient with a patent ductus arteriosus accompanied by marked pulmonary hypertension (Wood, 1958).

Right bundle branch block patterns have been reported in infants with patent ductus arteriosus (Ziegler, 1952; Nadas, 1957), but did not occur in our series.

Cardiac Catheterization. This procedure is as safe in infancy as in older patients. Over 50 infants have been catheterized in this clinic without any complication.

Catheterization was done only when the diagnosis could not be established after clinical, radiographic and electrocardiographic examination. In such cases the pulmonary artery pressure is usually at or 
near systemic level. The diagnosis of patent ductus arteriosus is often established by passing the catheter through the ductus, which is usually large in such cases, and the presence of a left to right shunt and any right to left shunt can be confirmed by blood oxygen estimations. If, however, the pulmonary artery pressure is at systemic level and the catheter cannot be passed through a ductus or enters a branch of the aorta, usually the right subclavian artery, then further investigation by angiography or aortography is required to differentiate the lesion from patent ductus arteriosus, aortopulmonary window or a high ventricular septal defect in which there was no rise in oxygen saturation at ventricular level.

Angiography. Venous angiocardiography will demonstrate dilution of dye in the pulmonary artery when a patent ductus arteriosus or aortopulmonary window is present if there is a left to right shunt. It may, however, fail to outline a common truncus adequately and has largely been replaced in this unit by selective angiocardiography.

Aortography. Injection into the brachial artery may show a shunt from aorta to pulmonary artery but fail to outline a common truncus. Retrograde aortography when the dye is injected through a catheter with the tip lying above the aortic valves is probably the best way of differentiating the various lesions when the right ventricular pressure is at systemic level. This investigation has a $4 \%$ mortality (Bauersfeld et al., 1957) and has not been used in this clinic.

\section{Treatment}

It is generally accepted that patent ductus arteriosus should be treated surgically. If symptoms are severe early operation is essential. In the absence of symptoms, Carter and Waterston (1951) advise operation shortly before children start school. We favour earlier surgery when the diagnosis is established in infancy and have advised operation in this age group even though the infants have few symptoms. Spontaneous closure of the ductus is rare, recurrent bronchitis is common, and growth and physical development are often retarded. Infants tolerate operation very well and seem less disturbed by admission to hospital than toddlers and young children.

When the ducts are small they are doubly ligated and in addition transfixed; when large (over $10 \mathrm{~mm}$.) they are divided.

It is important that operation should not be undertaken during a respiratory infection or in the presence of heart failure. Even when the ductus is large the patient responds to treatment with digoxin and diuretics, and it is our experience that if congestive cardiac failure persists after medical treatment there is some other lesion present.

\section{SUMMARY}

The findings in 28 infants in whom a patent ductus arteriosus was the sole cardiac abnormality are reviewed in an attempt to define the clinical features in infancy and to assess the value of routine radiography and electrocardiography.

The different clinical findings in small and large patent ducts are illustrated and the similarity of this lesion to some cases of persistent truncus arteriosus in the early months of life is described. The pitfalls caused by an overcompensating ductus are discussed.

The indications for cardiac catheterization and angiocardiography and their value in differential diagnosis are also considered. The problems of surgical treatment are mentioned.

We are indebted to Professor J. D. Hay for his advice and criticism of this paper, to Mr. F. R. Edwards and Mr. B. J. Bickford who operated on these cases, and to anaesthetists, Dr. G. J. Rees and Dr. A. Stead. We are also grateful to Dr. Norah Walker and Dr. C. M. Davies for their help in interpretation of the radiographs and angiocardiograms.

\section{REFERENCES}

Abbott, Maud E. (1937). In Nelson Loose-Leaf Medicine, Vol. 4, p. 207. New York.

Anderson, R. C., Adams, P. and Varco, R. L. (1956). Patent ductus arteriosus with reversal of flow. Pediatrics, 18, 410.

Bauersfeld, S. R., Adkins, P. C. and Kent, E. M. (1957). Patent ductus arteriosus in infancy. J. thorac. Surg., 33, 123.

Carter, R. E. Bonham and Waterston, D. (1951). The treatment of patent ductus arteriosus in infants under the age of five years. Arch. Dis. Childh., 26, 272.

Cosh, J. A. (1957). Patent ductus arteriosus. A follow-up study of 73 cases. Brit. Heart J., 19, 13.

Dammann, J. F. and Sell, C. G. R. (1952). Patent ductus arteriosus in the absence of a continuous murmur. Circulation, 6, 110.

Gibson, G. A. (1900). Clinical Lectures on Circulatory Affections. Lecture 1. Persistence of the arterial duct and its diagnosis. Edinb. med. J., n.s. 8, 1.

Hay, J. D. and Ward, O. C. (1956). Patent ductus arteriosus. A review of 108 cases treated surgically. Arch. Dis. Childh. A1, 279 .

Keith, J. D., Rowe, R. D. and Vlad, P. (1958). Heart Disease in Infancy and Childhood, p. 140 . Macmillan, New York.

Nadas, A. S. (1957). Pediatric Cardiology, p. 360 . Saunders, Philadelphia.

Reinhold, J. D. L. (1958). Heart disease in infancy and early childhood. In Modern Trends in Paediatrics (Second Series), p. 99. Butterworth, London.

and Nadas, A. S. (1954). The role of auscultation in the diagnosis of congenital heart disease. A phonocardiographic study of children. Amer. Heart J., 47, 405.

Rudolph, A. M., Mayer, F. E., Nadas, A. S. and Gross, R. E. (1958). Patent ductus arteriosus. A clinical and hemodynamic study of 23 patients in the first year of life. Pediatrics, 22, 892.

Wood, P. (1958). The Eisenmenger syndrome. Brit. med. J., 2, 701 .

Ziegler, R. F. (1951). Electrocardiographic Studies in Normal Infants and Children. Thomas, Springfield, Illinois.

(1952). The importance of patent ductus arteriosus in infants. Amer. Heart J., 43, 553. 